\title{
Oral Candida Albicans Colonization in Dental Prosthesis Patients and Individuals with Natural Teeth, Sana'a City, Yemen
}

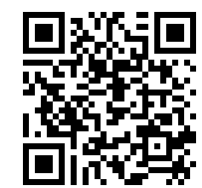

\author{
Omar Ahmed Esma'il Al-Dossary and Hassan A Al-Shamahy* \\ Medical Microbiology and Clinical Immunology, Faculty of Medicine and Health Sciences, Sana'a University, Yemen
}

Received: 眥: November 10, 2018; Published: 制: November 20, 2018

*Corresponding author: Hassan A Al-Shamahy, Medical Microbiology and Clinical Immunology, Faculty of Medicine and Heath Sciences, Sana'a University, Yemen

\begin{abstract}
Background: The capability of the Candida albicans Candida (CAC) to colonize surfaces can be signify as a risk factor for oral infection, thus, denture wearing approves of a stable factor that can affect oral health status.

Objectives: This study investigated risk factors associated with progress to Candida-related denture colonization in dental prosthesis comparing to individuals with natural teeth.

Methods: A total of 208 subjects were studied: 104 denture wearers and 104 non-denture wearers, matched by age and sex, comprised the experimental and control groups, respectively. Each subject was directed to perform oral rinsing using a phosphate-buffered saline solution, which was expectorated and processed for the recovery of Candida species on Sabouraud's dextrose agar. Isolates were identifying by culturing on chromogenic Candida agar and noting species-specific colony characteristics.

Results: There was a significant oral Candida albicans colonization rate (OCAC) among denture wearers equaled to $61.5 \%$ comparing with $33.6 \%$ among non-denture wearers with a significant association $(\mathrm{OR})$ of $\mathrm{OCAC}=3.2$, and $\mathrm{PV}<0.001$. Plus, there were significant association between $\mathrm{OCAC}$ and male denture wearers $(\mathrm{OR}=2.8, \mathrm{PV}<0.001$ ), increase of patient age ( $\geq 65$ years $\mathrm{OR}=2.2, \mathrm{PV}=0.01)$ and wearing complete denture (OR=2.6, $\mathrm{PV}=0.02$ ). Conclusions: Based on the results of this study ability of OCAC were greater in denture wearers than non-denture wearers, also greater risk of OCAC found with males, older ages and wearing complete denture. In addition, the study results are important for understanding OCAC in dentures and development strategies to reduce or eliminate OCAC in denture wearers.
\end{abstract}

Keywords: Oral C.albicans colonization (OCAC); Denture; Natural Teeth; Risk Factors; Yemen

\section{Introduction}

Dentures have an effect on the features of the oral cavity microenvironment, change to the oral mucosa can outcome from denturemediated mechanical tenderness or inflammation stimulated by denture-related materials [1-4]. Additionally, biofilm development on denture surfaces, go together with subsequent allergic reactions resultant from microbial colonization and/or their secreted metabolites [5-7]. Candida species found to be in 25-50\% of the oral cavity of healthy persons, are one of the main causes of microorganism biofilm formation on dentures and catheters and isolated from about $80 \%$ of the microorganisms isolated from the oral mucosa of denture wearers [5]. Even though Candida albicans is commonly associated with denture use, other Candida species are commonly isolated from underlying mucosal tissues and dentures [8]. Candida colonization and biofilm formation on dentures can be additional influenced by the species of colonizing Candida, oral hygiene practices, and denture character $[9,10]$. Personal hygiene, for instance denture removal at night, denture cleanser use, and smoking have been shown to affect colonization and dentureassociated stomatitis [2,3,6,10-12]. Furthermore, denture-related structural factors, including vertical dimensions, material integrity and fit, influence yeast colonization and subsequent denturerelated stomatitis $[6,10,13,14]$. It is well-known stomatitis has been reported in higher rate in denture wearers, and even though it is in general asymptomatic, it is associated with pseudo membrane (thrush), leukoplakia, formation, angular cheilitis and erythema [15]. This research aimed to study the Candida albicans occurrence rate in the oral cavity of denture wearer patients in comparison to those with natural teeth, to reveal the risk factors other than denture wearer for contracting Candida albicans on the oral mucosal membrane and tissue-fitting surface (mucosal surface) of dentures. 


\section{Subjects and Laboratory Methods}

\section{Subject Selection}

A total of two hundred and eight persons, were included in this study, 104 of them were denture wearer patients (cases group) while the other 104 adults with natural teeth (controls group), whom been selected randomly from Al-Thawrah hospital, Al-Gumhory hospital and Dental centers in Sana'a city, Yemen. The duration of the study was six months period, started in August 2017 and ended in February 2018. Inclusion criteria for subject selection were healthy individuals with no clinical signs of Candida infection and no systemic disease. In addition, individuals who smoked, currently taking antifungal, steroids, antibiotics, or immunosuppressive drugs in the past 6 months were excluded.

\section{Collection and Identification of Samples}

Salivary samples were collected using the oral rinse technique [16]. In brief, each subject was asked to rinse the mouth for 60 seconds with $10 \mathrm{ml}$ of sterile phosphate-buffered saline (PBS; $0.01 \mathrm{M}$ phosphate-buffered saline solution, $\mathrm{pH} 7.2$ ) and expectorate the wash into a $15 \mathrm{ml}$ sterile container [17]. Individuals who had removable dentures were asked to take out the denture prior to samples collection. The samples were immediately transported on ice to the microbiology laboratory. Each oral rinse was centrifuged at $3500 \mathrm{rpm}$ for 10 minutes, and then the supernatant was discarded. The pellet was re-suspended in $1 \mathrm{ml}$ sterile PBS. One hundred $\mu \mathrm{l}$ of the concentrated oral rinse was inoculated onto Sabouraud's dextrose agar and incubated at $37^{\circ} \mathrm{C}$ for 48 hours. The lasting samples were stored at $-20^{\circ} \mathrm{C}$. If Candida colonies appeared on the Sabouraud's dextrose agar, then chromogenic Candida agar was inoculated using $100 \mu$ l of the oral rinse supernatant and incubated for 48 hours for colonies study. Candida species were identified by the color of the colonies using the color reference guide supplied by the manufacturer. When color identification was unclear, fermentation assay of sucrose, maltose, glucose, lactose and galactose was done. The Candida species were also identified by the ability to produce chlamydo-spores on glutinous rice agar [18].

\section{Data Analysis}

Data were statistically analyzed using the EPI-Info program version 6. The difference in distribution of the Candida albicans between groups was based on comparison of frequency distributions by a chi-square test. A p value $<0.05$ was considered significant.

\section{Ethical Approval}

We obtained written consent from all cases. Assent was taken from participants before collecting the specimens. The study proposal was evaluated and approved by the Ethics Committee of Faculty of Medicine and Health Sciences, Sana'a University.

\section{Result}

There was a significant oral carriage rate of Candida albicans among denture wearers (cases) equaled to $61.5 \%$ comparing with $33.6 \%$ among non-denture wearers (controls) with a significant association between denture wearing and a contract of oral carriage of Candida albicans (OR=3.2, $\mathrm{PV}<0.001$ ). When sex of participants considered, there was a significant oral carriage rate of Candida albicans among male denture wearers equaled to $65.2 \%$ comparing with $36.9 \%$ among male of non-denture wearers with a significant association between male denture wearers and a contract of oral carriage of Candida albicans ( $\mathrm{OR}=2.8, \mathrm{PV}<0.001$ ), while there was no significant oral carriage rate of Candida albicans among female denture wearers equaled to $33.3 \%$ comparing with $8.3 \%$ among female of non-denture wearers with non-significant association between female denture wearers and a contract of oral carriage of Candida albicans $(\mathrm{OR}=4,1, \mathrm{PV}=0.17)$ (Table 1$)$. In addition, when ages of cases (denture wearers) were considered, there was a significant increase of oral $C$. albicans colonization with an increase of age in denture wearer group in which the highest rate of $C$. albicans colonization was in age group of $\geq 65$ years $(78.3 \%, \mathrm{PV}=0.01)$, and the lowest was at age group $<45$ years $(20 \%)$. Also, a significant association of contracting oral carriage of Candida albicans equal to 2.2 times was found for $\geq 65$ years age group ( $\mathrm{PV}<0.001$ ) (Table $1)$. When we considered the type of dental prosthesis, there was a significant oral carriage rate of Candida albicans among complete denture wearers equaled to73.9\% comparing with51.7\% among partial denture wearers with a significant association of contracting oral carriage of Candida albicans for complete denture equal to 2.6 times (PV=0.02). When we considered the materials of dental prosthesis, there was no significant differences between the oral carriage rate of Candida albicans in patients had acrylic denture and/or patients had chrome cobalt denture $(60.3 \%$ and $64.5 \%$ respectively, $\mathrm{PV}=0.68$ ) (Table 2).

Table 1: The carriage rate of Candida albicans in cases and controls and associated OR for different sexes and age groups.

\begin{tabular}{|c|c|c|c|c|c|c|c|c|c|}
\hline \multirow{2}{*}{\multicolumn{2}{|c|}{ Factors }} & \multicolumn{2}{|c|}{ Cases $(n=104)$} & \multicolumn{2}{|c|}{ Controls $(n=104)$} & \multirow{2}{*}{ OR } & \multirow{2}{*}{ CI } & \multirow{2}{*}{$\chi^{2}$} & \multirow{2}{*}{ PV } \\
\hline & & No. & $\%$ & No. & $\%$ & & & & \\
\hline \multicolumn{2}{|c|}{ Male } & $60 / 92$ & 65.2 & $34 / 92$ & 36.9 & 2.8 & $1.6-4.9$ & 13 & $<0.001$ \\
\hline \multicolumn{2}{|c|}{ Female } & $4 / 12$ & 33.3 & $1 / 12$ & 8.3 & 4.1 & $0.4-37$ & 1.8 & 0.17 \\
\hline \multirow{4}{*}{ Age group } & $<45$ years & $2 / 10$ & 20 & $1 / 10$ & 10 & 2 & $0.2-22.6$ & 0.3 & 0.5 \\
\hline & $45-54$ years & $6 / 16$ & 37.5 & $3 / 16$ & 18.8 & 2.1 & $0.5-8.4$ & 1.04 & 0.3 \\
\hline & $55-64$ years & $20 / 32$ & 62.5 & $11 / 32$ & 34.4 & 2 & $1.0-4.4$ & 3.9 & 0.05 \\
\hline & $\geq 65$ years & $36 / 46$ & 78.3 & $20 / 46$ & 43.5 & 2.2 & $1.2-4.2$ & 6.2 & 0.01 \\
\hline \multicolumn{2}{|c|}{ Total } & $64 / 104$ & 61.5 & $35 / 104$ & 33.6 & 3.2 & $1.8-5.6$ & 16.2 & $<0.001$ \\
\hline
\end{tabular}

OR: Odds ratio $=$ Relative risk 
95\%CI: 95\% Confidence intervals

$\chi^{2}$ Chi-square $=3.9$ or more is significant

PV: Probability value $=0.05$ or less is significant

Table 2: The type of dental prosthesis factors that associated with colonization of Candida albicans among denture wearer patients.

\begin{tabular}{|c|c|c|c|c|c|c|}
\hline \multirow[t]{2}{*}{ Factors } & \multicolumn{2}{|c|}{$\begin{array}{l}\text { Positive Candida albicans } \\
(n=64)\end{array}$} & \multirow[t]{2}{*}{ OR } & \multirow[t]{2}{*}{ CI } & \multirow{2}{*}{$\chi^{2}$} & \multirow[t]{2}{*}{ PV } \\
\hline & No. & $\%$ & & & & \\
\hline \multicolumn{7}{|c|}{ Type of dental prosthesis } \\
\hline complete $n=46$ & 34 & 73.9 & 2.6 & 1.1-6.1 & 5.3 & 0.02 \\
\hline Partial $n=58$ & 30 & 51.7 & 0.37 & $0.16-0.8$ & 5.3 & 0.02 \\
\hline Acrylic $n=73$ & 44 & 60.3 & 0.83 & $0.3-1.9$ & 0.16 & 0.68 \\
\hline Chrome cobalt $n=31$ & 20 & 64.5 & 1.2 & $0.5-2.8$ & 0.16 & 0.68 \\
\hline
\end{tabular}

OR: Odds ratio $=$ Relative risk

95\% CI: 95\% Confidence intervals

$\chi^{2}$ Chi-square $=3.9$ or more is significant

PV: Probability value $=0.05$ or less is significant

\section{Discussion}

Denture-related stomatitis has a multi-factorial etiology that is associated with denture use, and disease presentation is affected mostly by host factors and exogenous factors as introducing prosthesis [6]. Many studies have discussed the involvement of Candida albicans in the establishment and persistence of such disease since the acrylic denture fitting surfaces seem to facilitate the adherence of this micro-organism [19]. The present study confirmed these finding in which a significant association $(\mathrm{PV}<0.001)$ between denture wearing and OCAC rate $161.5 \%$ for denture wearers diverse $33.6 \%$ for natural teeth controls) with associated risk factor of denture wearing equal to 3.2 times (Table 1). Our significant heavy OCAC among denture wearers (61.5\%) is similar to that reported by Daniluk et al. [20] in which denture wearers showed a $67 \%$ rate of OCAC. This result can be explained by the fact that denture wearing, and poor denture hygiene, particularly wearing the denture continually rather than removing them during sleep is another risk factor, both for candidal carriage and for oral candidiasis [21]. Also, dentures provide a relative acidic, moist and anaerobic environment because the mucosa coated by the denture is sheltered from oxygen and saliva [22]. Other cause for colonization of Calbicans in denture wearing persons is that loose, poorly fitting dentures may also cause minor trauma to the mucosa which is thought to enhance the permeability of the mucosa and increase the ability of $C$. albicans to invade the tissues $[7,22,23]$. These conditions all support the growth of $C$. albicans. Every so often dentures turn into much worn, or they have been made to allow insufficient lower facial height (occlusal vertical dimension), directed to over-closure of the mouth (an appearance sometimes described as "collapse of the jaws"). This leads to the skin folds at the corners of the mouth, in result generating an intertriginous area where angular cheilitis and another form of candidiasis, can develop [24].
In this study, the data support the rejection of the null hypothesis that there would be no difference between male and female denture wearers in terms of the prevalence of DRS and colonization by Candida albicans of the inner surfaces of dentures and attachment surroundings. However, there was a significant oral carriage rate of Candida albicans among male denture wears (cases) equal to $65.2 \%$ comparing with $39.9 \%$ among non-denture wears male (controls). In addition, there was significant association between denture wearing in male group and contract of oral carriage of Candida albicans with OR equal to 2.8 times ( $\mathrm{PV}<0.001)$. While in female group, there was no significant differences (Table 1).

Since dentures and age-related immunosuppression are both well-known risk factors associated with candidiasis development, there was significant increase of oral Candida albicans colonization with increase of age in denture wearers in the present study (Table 1). While our result is different from that reported from Philadelphia by Bouquot et al. [25] in which no different in the rate of mouth colonization occurred with different ages of denture wearer patients, but similar to that reported from UK by Smaancyake [23] in which the highest rate of OCAC occurred in older adult age groups.

When we considered the type of dental prosthesis, there was a significant oral carriage rate of Candida albicans among complete denture wearers equaled to $73.9 \%$ comparing with $51.7 \%$ among partial denture wearers with a significant association of contracting oral carriage of Candida albicans of complete denture equal to 2.6 times $(\mathrm{PV}=0.02$ ) (Table 2). Our results are similar to that reported previously in several studies $[1,6,7,23,26]$. When we considered the materials of dental prosthesis in the present study, there was similar oral carriage rate of Candida albicans in patients had acrylic denture or patients had chrome cobalt denture $(60.3 \%$ and $64.5 \%$ respectively) (Table 2). This result is different from the 
findings of Williams and Lewis [26] in which Candida species were capable of adhering to the surface of dentures, most of which are made from polymethyl-acrylate, and they refer this colonization to present of micro-fissures and cracks in the surface of dentures that aid micro-organisms to form biofilm. Intra-oral prostheses may therefore become covered in a biofilm [26] and act as reservoirs of infection [27], continually re-infecting the mucosa. For this reason, disinfecting the denture is a vital part of treatment of oral candidiasis in persons who wear dentures, as well as correcting other factors like not enough lower facial height and fit of the dentures [22].

\section{Conclusion}

Based on the results of this study ability of CAC were greater in denture wearers than non-denture wearers, also greater risk of CAC were found with males, older ages and complete denture. In addition, our results are important for the development of strategies to for eliminate these indicators of risk and significantly reduce Candida albicans colonization and oral Candida infections in denture wearers.

\section{References}

1. Abbas Ali Jafari, Mohammad Hossein Lotfi-Kamran, Abbas Falah-Tafti, Saeeb Shirzadi (2013) Distribution Profile of Candida Species Involved in Angular Cheilitis Lesions Before and After Denture Replacement. Jundishapur Journal of Microbiology 6(6): e10884.

2. Budtz-Jorgensen E (1981) Oral mucosal lesions associated with the wearing of removable denture. J Oral Path 10(2): 65-80.

3. Al-Kebsi AM, Othman AM, Abbas AM (2017) Oral C.albicans colonization and non-candida albicans candida colonization among university students, Yemen. Universal Journal of Pharmaceutical Research 2(5): $1-5$.

4. Arendorf TM, Walker DM (1987) Denture stomatitis: A review. J Oral Rehabil 14(3): 217-227.

5. Dar-odeh NS, Shehabi AA (2003) Oral candidiasis in patients with removable dentures. Mycoses 46(5-6): 187-191.

6. Al-Sanabani Nesreen F, Al-Kebsi Abbas M, Al-Shamahy Hassan A, Abbas Al-Kasem MA (2018) Etiology and risk factors of stomatitis among Yemeni denture wearers. Universal Journal of Pharmaceutical Research 3(1): 69-73.

7. Abbas AM, Al-Kebsi MA, Mohammed AM, Al-Shamahy HA (2015) Prevalence of different types of bacterial and fungal oral infections among patients attending dental clinics in Sana'a city- Yemen. Faculty of Sciences Bulletin 27: 1-15.

8. Al-Haddad KA, Al-dossary OAE, Al-Shamahy HA (2018) Prevalence and associated factors of oral Non-Candida albicans Candida carriage in Denture wearers in Sana'a City-Yemen. Universal Journal of Pharmaceutical Research 4(4): 69-73.

9. Fenlon MR, Sherriff M, Walter JD (1983) Factors associated with the presence of denture related stomatitis in complete denture wears: A preliminary investigation. Eur J Prosthet Dent 6(4): 145-147.
10. Figueiral MH, Azul A, Pinto E (2007) Denture-related stomatitis: Identifi cation of aetiological and predisposing factors - a large cohort. J Oral Rehabil 34(6): 448-455.

11. Dagistan S, Aktas AE, Caglayan F (2009) Differential diagnosis of denture-induced stomatitis, Candida and their variations in patients using complete denture: A clinical and mycological study. Mycoses 52(3): 266-271.

12. Tavakol P, Emdadi S (2001) Evaluation of prevalence of oral candidiasis in patients using complete denture wears. Tehran Uni Med J 59(1): 8690.

13. Pereira Cenci T, Del Bel Cury AA, Crielaard W (2008) Development of Candida - associated denture stomatitis: New insights. J Appl Oral Sci 16(2): 86-94.

14. Von Fraunhofer JA, Loewy ZG (2009) Factors involved in microbial colonization of oral prostheses. Gen Dent 57(2): 136-143.

15. Greenberg MS, Glick M, Ship JA (2008) Burket's Oral Medicine: Diagnosis and Treatment $\left(11^{\text {th }}\right.$ edn); Ontario: BC Decker Inc.

16. Coulter WA, Kinirons MJ, Murray SD (1993) The use of a concentrated oral rinse culture technique to sample oral candida and lactobacilli in children and the relationship between Candida and Lactobacilli levels and dental caries experience: A pilot study. Int J Paediatr Dent 3(1): 1721.

17. MacFarlane TW, Samaranayake LP, Williamson MI (1987) Comparison of Sabouraud dextrose and Pagano-Levin agar media for detection and isolation of yeasts from oral samples. J Clin Microbiol 25(1): 162-164.

18. Staib P, Morschhäuser J (2007) Chlamydospore formation in Candida albicans and Candida dubliniensis - an enigmatic developmental programme. Mycoses 50(1): 1-12.

19. Moura JS, da Silva WJ, Pereira T, Del Bel Cury AA, Garcia RCR (2006) Influence of acrylic resin polymerization methods and saliva on the adherence of four Candida species. J Prosthet Dent 96(3): 205-211.

20. Daniluk T, Tokajuk G, Stokowska W (2006) Occurrence rate of oral Candida albicans in denture wearer patients. Adv Med Sci 51(1): 77-80.

21. Kerawala C, Newlands C (2010) Oral and maxillofacial surgery. Oxford: Oxford University Press, pp. 447.

22. Tarçın BG (2011) Oral candidiasis: Etiology, clinical manifestations, diagnosis and management. MÜSBED 1(2):140-148.

23. Samaranayake LP (2009) Essential microbiology for dentistry ( $3^{\text {rd }}$ edn); Elseveier pp. 178-297.

24.Zomorodian Kamiar, Neda Nejabat Haghighi, Naeem Rajaee, Keyvan Pakshir, Bita Tarazooie, et al. (2011) Assessment of Candida species colonization and denture-related stomatitis in complete denture wearers. Medical Mycology 49(2): 208-214.

25. Bouquot Brad, W Neville, Douglas D Damm, Carl M Allen, Jerry E (2002) Oral and maxillofacial pathol. ( $2^{\text {nd }}$ edn) Philadelphia: WB Saunders, pp. 189-197.

26. Williams D, Lewis M (2011) Pathogenesis and treatment of oral candidiasis. J of oral microbial 3: 1-5.

27. Treister NS, Bruch JM (2010) Clinical oral medicine and pathology. Humana Press, New York, USA, p. 93. 


\section{ISSN: 2574-1241}

DOI: 10.26717/BJSTR.2018.11.002072

Hassan A Al-Shamahy. Biomed J Sci \& Tech Res

(C) (i) This work is licensed under Creative

Submission Link: https://biomedres.us/submit-manuscript.php

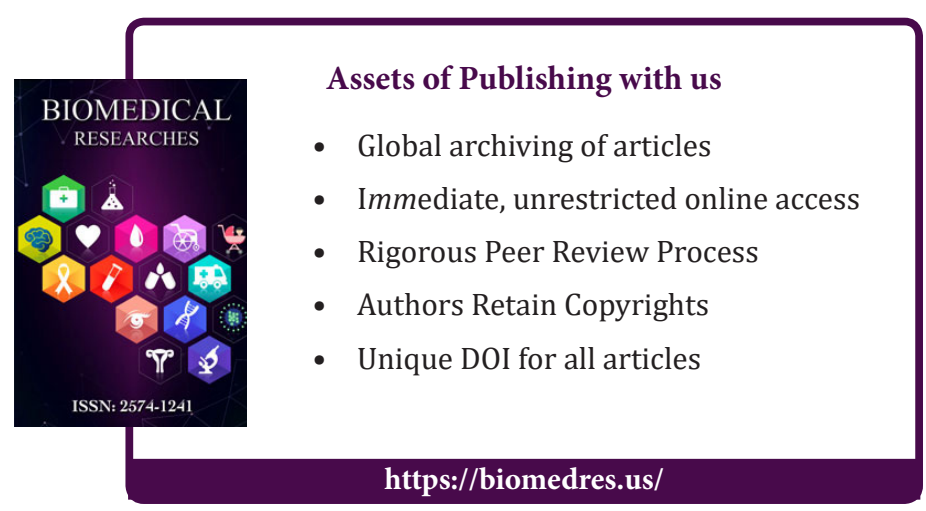

